\title{
Epidural analgesia as part of a fast track recovery (ERAS) program for elective colonic surgery: just long enough
}

\author{
Jasper Koolwijk ${ }^{*}$, Josephien PJM Backx², Robbert C. Bremer ${ }^{3}$, Sanne Kleinveld ${ }^{4}$ and Gerrit J. Noordergraaf ${ }^{3}$ \\ *Correspondence: j.koolwijk@elisabeth.nl \\ 'Intern, Department of Anesthesiology, St. Elisabeth Hospital, Tilburg, Hilvarenbeekseweg 60, 5022 GC The Netherlands. \\ ${ }^{2}$ Nurse, Department of Anesthesiology, St. Elisabeth Hospital, Tilburg, Hilvarenbeekseweg 60, 5022 GC The Netherlands. \\ ${ }^{3}$ Anesthesiologist, Department of Anesthesiology, St. Elisabeth Hospital, Tilburg, Hilvarenbeekseweg 60, 5022 GC The Netherlands. \\ ${ }^{4}$ Fellow, Department of Surgery, St. Elisabeth Hospital, Tilburg, Hilvarenbeekseweg 60, 5022 GC The Netherlands.
}

\begin{abstract}
Background: Epidural analgesia (EA) has been suggested to be a key element within the enhanced recovery after surgery guidelines for elective colonic surgery (ERAS). However, divergent descriptions exist concerning the optimal duration of epidural analgesia in ERAS. Our study objective was to investigate associations between epidural analgesia duration, length of stay and complication rate, focusing on the value of a third or fourth day of use.

Methods: In retrospective analysis, 243 patients who underwent elective colonic surgery according to ERAS and received EA as postoperative analgesic regimen between 2009 and 2012 were studied. Data were pooled according to the duration of EA, groups 1 to 4 : $\leq 24 \mathrm{~h},>24$ to $\leq 48 \mathrm{~h},>48$ to $\leq 72 \mathrm{~h}$ and $>72 \mathrm{~h}$, respectively. Length of stay (LOS) in days, complication rate, patient controlled intravenous analgesia (PCIA) opioid consumption, reason for termination of EA and other characteristics were documented.

Results: Overall median LOS was 7.9 days, interquartile range (IQR) 7. LOS differed among the 4 groups $(p<0.001)$ and was significantly higher in group 4 (19.3, IQR 21) compared to all other groups (1 to 3 respectively: 9.0, IQR 8, $p=0.036$; 6.8, IQR 6, $p<0.001 ; 7.0$, IQR $6, p<0.001)$. Median LOS in group 2 was also significantly lower compared to group 1 ( $p=0.033)$. No differences were found comparing group 3 to groups 1 and $2(p=0.129 ; p=0.224)$. Overall median complication rate was 0 , IQR 1 , and differed among the 4 groups ( $p=0.001)$. It was significantly higher in group 4 ( $1, \mathrm{IQR} 2)$ compared to all other groups ( 1 to 3 respectively: 1 IQR 2, $p=0.040 ; 0$, IQR $1, p=0.005 ; 1$, IQR 2, $p<0.001$ ). Opioid consumption through PCIA after termination of EA differed significantly between group 1 and group 2 while its duration did not $(87.8 \pm 35.2 \mathrm{mg}$ vs. $62.4 \pm 39.3 \mathrm{mg}, p=0.025 ; 54.8 \pm 19.2 \mathrm{hrs}$ vs. $45.1 \pm 21.2$ hrs, $p=0.094)$.

Conclusions: Maintaining epidural analgesia (EA) beyond 48 hours postoperatively is not associated with prolonged LOS or an increased complication rate. The third 24 hour period decreases change-over to PCIA. However, prolongation of EA beyond 72 hours is associated with increased LOS and complication rate within the conglomerate of factors in the ERAS clinical pathway in this exploratory study.
\end{abstract}

Keywords: Epidural analgesia, fast-track surgery, length of stay, colonic surgery, postoperative analgesia, patient controlled intravenous analgesia

\section{Background}

A recent study reported the implementation of the enhanced recovery after surgery guidelines for elective colonic surgery (ERAS) in The Netherlands [1]. It showed a decreased median length of stay (LOS) in ERAS patients when compared to those receiving traditional perioperative care [1]. ERAS is an example of bundling individual, often not or only weakly, evidence-based elements into a strong conglomerate which, together with an increase in procedural attention, form a new standard in care or called 'clinical pathway'. In ERAS, many of the pre-, intra- and postoperative aspects are anesthesia driven and include a policy of brief fasting, emphasis on short-acting anesthetic agents, avoidance of salt and fluid loading, preference for NSAID's over opioid analgesia, rapid mobilization as well as emphasis on the use of intra- and postoperative epidural analgesia (EA) [2].

ERAS recommends EA usage and its supervision by an acute pain service (APS) for 48 to 72 hours. Historically, acute pain and its systemic inflammatory response is deemed an issue for the first 72 hours. However, Gillissen et al., (2013) described the removal of EA on postoperative day 2 ( $\approx 48$ hours) in the Dutch implementation study [1]. While ERAS seems clear about the desirability of EA in general, it does not offer insight into the value-add of EA versus its potential hinder as a function of duration of usage: EA may hinder the expression of other factors, as it may limit mobilization, require a urinary catheter or an open IV-access.

The purpose of this study was to investigate the relationship of EA duration to LOS, focusing on the value of a third or even fourth 24-hour period in patients with EA, treated according to ERAS.

\section{Methods \\ Data collection}

After receiving the local ethics committee's permission for this

(C) 2013 Koolwijk et al; licensee Herbert Publications Ltd. This is an Open Access article distributed under the terms of Creative Commons Attribution License (http://creativecommons.org/licenses/by/3.0). This permits unrestricted use, distribution, and reproduction in any medium, provided the original work is properly cited. 


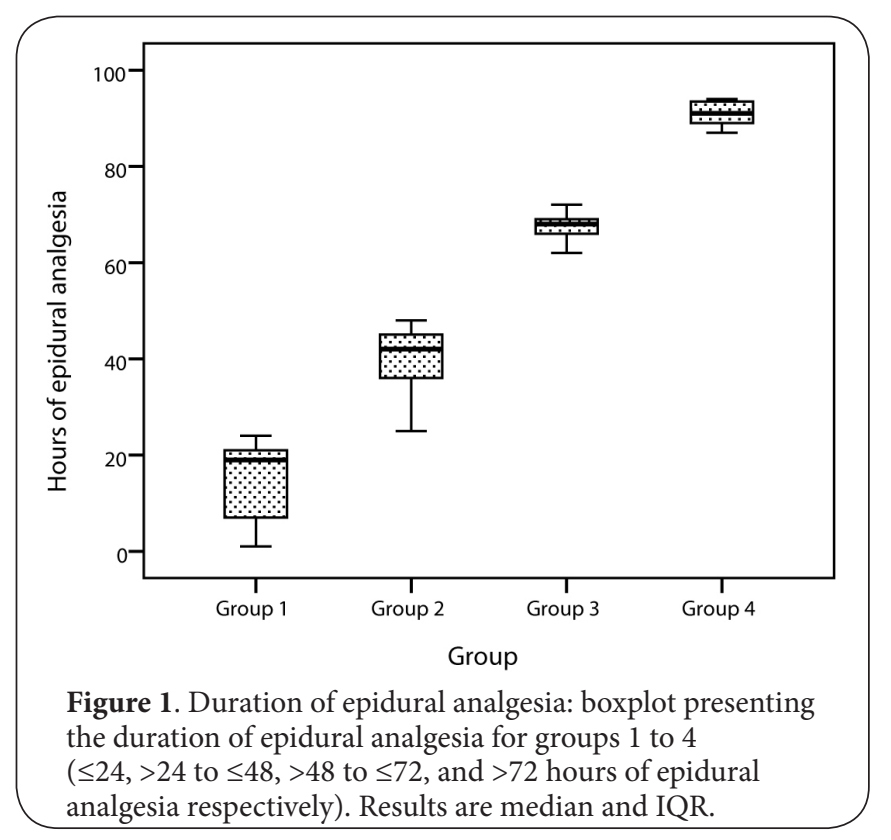

retrospective observational, single-institution study, data from all patients who received epidural analgesia (EA) as part of ERAS occurring from January 1, 2009 through July 31, 2012 were gathered using the patient data management system (PDMS) (MetaVision Suite version 5.46.38,iMDsoft), the APS database, ward reports and notes, Electronic Patients File and classic anesthesia charts (patients operated before January 1 , 2010). In case of conflicting data between sources, the APS database was used. Data were coded and anonymized by one author (JK). Data collected reflecting the ERAS admission to 30 days after surgery.

\section{Patient discharge}

Specific criteria for discharge include: evaluation of health (vital parameters, including. $>0.5 \mathrm{ml} / \mathrm{kg} / \mathrm{hr}$ diuresis, lab results, all within (1.5x) range, corrected for age); no signs of infection, including no sub-febril temperature; defecation acceptable in combination with adequate oral intake (no nausea or vomiting in last 12 hours); able to move freely (corrected for pre-operative status and the situation being discharged to); supportive care arranged (eg., nursing visit at home). Adequate visual analog scale pain level on oral medication must be established. Within the period studied, no specific medical or organizational changes in case management were made. No transfer issues delaying departure were noted.

\section{Standard medication and epidural withdrawal}

All patients with EA received a ropivacaine $0,2 \%$ with sufentanil $0.5 \mu \mathrm{g} \cdot \mathrm{ml}^{-1}$ solution by continuous infusion with target treatment length of 72 hours. After 72 hours, EA was routinely terminated after patient evaluation and pain assessment. In case of forced early eg., ( $\leq 48$ hours: did not make it to day 3) epidural termination, the APS reported the reason for withdrawal as well as when EA was to be continued beyond 72 hours. If EA was followed by patient controlled intravenous analgesia (PCIA) this was done with piritramide $0,1 \%, 1 \mathrm{mg}$ per demand, with a six minute lock out period.

\section{Outcomes}

Primary outcome was LOS expressed in days. Secondary outcomes were complication rate defined as the number of registered complications within 30 days after surgery and opioid consumption of patients having received PCIA after termination of EA. The reason for termination of EA was documented.

\section{Statistical analysis}

Demographics (eg., gender, age, EA and surgical details), hours of epidural analgesia (HEA), LOS, and complications were documented. Cases were pooled into four groups: 0-24 HEA (group 1), $>24$ to $\leq 48$ HEA (group 2), $>48$ to $\leq 72$ HEA (group 3) and $>72$ HEA (group 4). Non-parametric data are described using median and interquartile range (IQR). Differences between groups were tested using Independent Samples Kruksal-Wallis test and Mann Whitney $U$ for pair wise comparisons. The Holm-Bonferroni correction was applied to correct for multiple testing. Parametric data are described as mean and SD, students' t-test was used to test for differences between groups. For all tests a $p$-value of $<0.05$ was considered significant. Statistical analysis was performed using SPSS v20 (IBM, Armonk New York USA).

\section{Results}

\section{Study description including characteristics}

During the study period the APS serviced 246 patients with EA as part of the ERAS procedure. Three cases were excluded due to incomplete or duplicated records. Median hours of epidural analgesia (HEA) for the groups were 19 hours $(n=43$, IQR 15), 42 hours ( $n=45$, IQR 12), 68 hours ( $n=131$, IQR 3 ) and 91 hours ( $n=24, I Q R 5)$, respectively. See Figure 1 and 2. Patient characteristics are shown in Table 1.

\section{LOS and complication rate}

Overall median LOS was 7.9 days, IQR 7. LOS differed between the 4 groups $(p<0.001)$. LOS was significantly higher in group 4 (19.3, IQR 21) compared to the other groups (9.0, IQR 8, $p=0.036 ; 6.8, \mathrm{IQR} 6, p<0.001 ; 7.0, \mathrm{IQR} 6, p<0.001$; groups 1 to 3 respectively). Median LOS in group 2 was significantly lower compared to group 1 ( $p=0.033$ ). No differences in LOS were found when comparing group 3 to groups 1 and 2 ( $p=0.129$; $p=0.224$ respectively). See Figure 3 .

A total of 237 complications were registered in 116 patients. Median complication rate was 0, IQR 1 overall, but differed among the 4 groups $(p=0.001)$. This rate was significantly higher in group $4(1, I Q R 2)$ compared to all other groups ( 1 to 3 respectively: $1, \mathrm{IQR} 2, p=0.04 ; 0, \mathrm{IQR} 1, p=0.005 ; 1$, IQR $2, p<0.001$ ) see Figure 4 . Surgically-oriented infections 


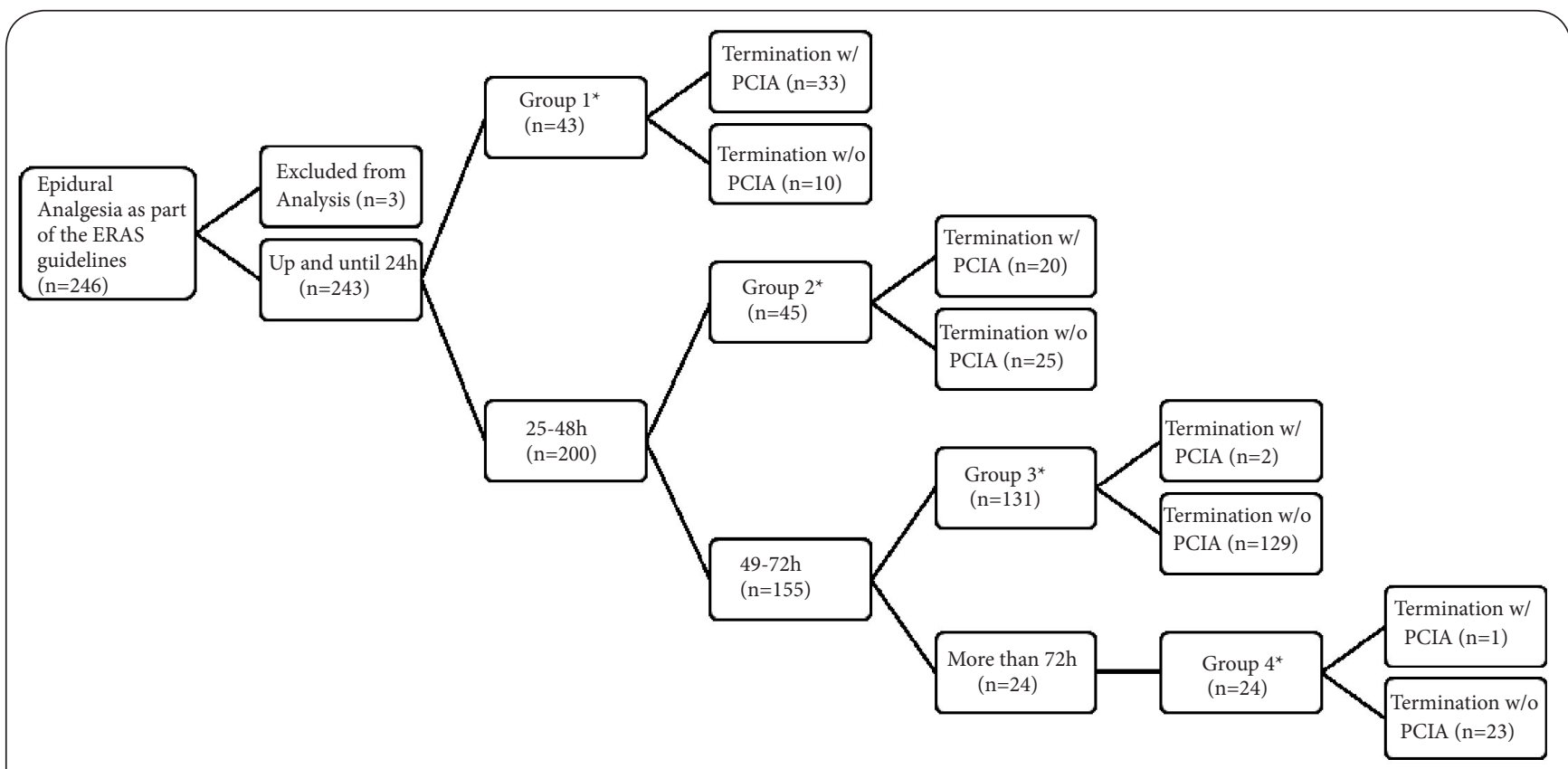

Figure 2. Flowchart describing the origin of patients in each group. ${ }^{\star}$ - group compared in the analysis. ERAS: enhanced recovery after surgery guidelines for elective colonic surgery; PCIA: patient controlled intravenous analgesia.

Table 1. Patients and epidural characteristics per group for groups 1 to $4(\leq 24,>24$ to $\leq 48,>48$ to $\leq 72$ and $>72$ hours of epidural analgesia respectively). Data are numbers and percentages unless otherwise noted.

\begin{tabular}{|c|c|c|c|c|c|c|c|c|c|c|c|c|}
\hline \multirow[b]{2}{*}{ Year } & \multirow[b]{2}{*}{2009} & \multicolumn{2}{|c|}{ Group 1} & \multicolumn{2}{|c|}{ Group 2} & \multicolumn{2}{|c|}{ Group 3} & \multicolumn{2}{|c|}{ Group 4} & \multicolumn{2}{|c|}{ Overall } & \multirow{2}{*}{$\frac{p^{*}}{\text { N.S. }}$} \\
\hline & & 18 & $41.9 \%$ & 8 & $17.8 \%$ & 39 & $29.8 \%$ & 7 & $29.2 \%$ & 72 & $29.6 \%$ & \\
\hline & 2010 & 14 & $32.6 \%$ & 16 & $35.6 \%$ & 46 & $35.1 \%$ & 3 & $12.5 \%$ & 79 & $32.5 \%$ & N.S. \\
\hline & 2011 & 7 & $16.3 \%$ & 11 & $24.4 \%$ & 37 & $28.2 \%$ & 10 & $41.7 \%$ & 65 & $26.7 \%$ & N.S. \\
\hline & 2012 & 4 & $9.3 \%$ & 10 & $22.2 \%$ & 9 & $6.9 \%$ & 4 & $16.7 \%$ & 27 & $11.1 \%$ & 0.021 \\
\hline Age $($ mean \pm SD) & & -- & $67 \pm 13$ & -- & $65 \pm 12$ & -- & $68 \pm 11$ & -- & $62 \pm 17$ & -- & $67 \pm 13$ & N.S. \\
\hline \multirow[t]{2}{*}{ Gender } & Male & 20 & $46.5 \%$ & 17 & $37.8 \%$ & 68 & $51.9 \%$ & 10 & $41.7 \%$ & 115 & $47.3 \%$ & N.S. \\
\hline & Female & 23 & $53.5 \%$ & 28 & $62.2 \%$ & 63 & $48.1 \%$ & 14 & $58.3 \%$ & 128 & $52.7 \%$ & N.S. \\
\hline \multirow[t]{3}{*}{ ASA } & ASA I/II & 34 & $79.1 \%$ & 29 & $64.4 \%$ & 96 & $73.3 \%$ & 18 & $75.0 \%$ & 177 & $72.8 \%$ & N.S. \\
\hline & ASA III/IV & 7 & $16.3 \%$ & 10 & $22.2 \%$ & 16 & $12.2 \%$ & 2 & $8.3 \%$ & 35 & $14.4 \%$ & N.S. \\
\hline & Not recorded & 2 & $4.7 \%$ & 6 & $13.3 \%$ & 19 & $14.5 \%$ & 4 & $16.7 \%$ & 31 & $12.8 \%$ & N.S. \\
\hline \multirow[t]{2}{*}{ Initial disposition } & Ward & 36 & $83.3 \%$ & 38 & $84.4 \%$ & 114 & $87.0 \%$ & 20 & $83.3 \%$ & 208 & $85.6 \%$ & N.S. \\
\hline & $\mathrm{MCU} / \mathrm{ICU}$ & 7 & $16.3 \%$ & 7 & $15.6 \%$ & 17 & $13.0 \%$ & 4 & $16.7 \%$ & 35 & $14.4 \%$ & N.S. \\
\hline \multirow[t]{4}{*}{ Level of Insertion. } & High Thoracic (Th2-Th7) & 3 & $7.0 \%$ & 2 & $4.4 \%$ & 6 & $4.6 \%$ & 4 & $16.7 \%$ & 15 & $6.2 \%$ & N.S. \\
\hline & Low Thoracic (Th8-Th12) & 25 & $58.1 \%$ & 22 & $48.9 \%$ & 76 & $58.0 \%$ & 10 & $41.7 \%$ & 133 & $54.7 \%$ & N.S. \\
\hline & Lumbar (L1-L4) & 7 & $16.3 \%$ & 13 & $28.9 \%$ & 32 & $24.4 \%$ & 7 & $29.2 \%$ & 59 & $24.3 \%$ & N.S. \\
\hline & Not recorded & 8 & $18.6 \%$ & 8 & $17.8 \%$ & 17 & $13.0 \%$ & 3 & $12.5 \%$ & 36 & $14.8 \%$ & N.S. \\
\hline \multirow[t]{8}{*}{ Type of surgery } & (Low-)Anterior/Rectal/Rectosigmoid Resection & 15 & $34.9 \%$ & 13 & $28.9 \%$ & 48 & $36.6 \%$ & 6 & $25.0 \%$ & 82 & $33.7 \%$ & N.S. \\
\hline & Hemicolectomy & 10 & $23.3 \%$ & $12^{\dagger}$ & $26.7 \%$ & $37^{\dagger}$ & $28.2 \%$ & 3 & $12.5 \%$ & 62 & $25.5 \%$ & N.S. \\
\hline & SigmoidResection & 11 & $25.6 \%$ & 7 & $15.6 \%$ & 26 & $19.8 \%$ & 6 & $25.0 \%$ & 50 & $20.6 \%$ & N.S. \\
\hline & Stoma Construction/Reversal & 2 & $4.7 \%$ & 4 & $8.9 \%$ & 7 & $5.3 \%$ & 3 & $12.5 \%$ & 16 & $6.6 \%$ & N.S. \\
\hline & (Subtotal) Colectomy/Proctocolectomy & 1 & $2.3 \%$ & 3 & $6.7 \%$ & 8 & $6.1 \%$ & 2 & $8.3 \%$ & 14 & $5.8 \%$ & N.S. \\
\hline & IleocecalResection & 3 & $7.0 \%$ & 2 & $4.4 \%$ & 3 & $2.3 \%$ & 0 & $0.0 \%$ & 8 & $3.3 \%$ & N.S. \\
\hline & (Exploratory) Laparotomy & 1 & $2.3 \%$ & 2 & $4.4 \%$ & 1 & $0.8 \%$ & 2 & $8.3 \%$ & 6 & $2.5 \%$ & N.S. \\
\hline & Others & 0 & $0.0 \%$ & 2 & $4.4 \%$ & 1 & $0.8 \%$ & 2 & $8.3 \%$ & 5 & $2.1 \%$ & N.S. \\
\hline
\end{tabular}

*: after Bonferonni correction. $\uparrow: 1$ of these surgeries was done laparoscopic; ICU: Intensive care unit; MCU: Medium care unit; Th: Thoracic; L: Lumbar 


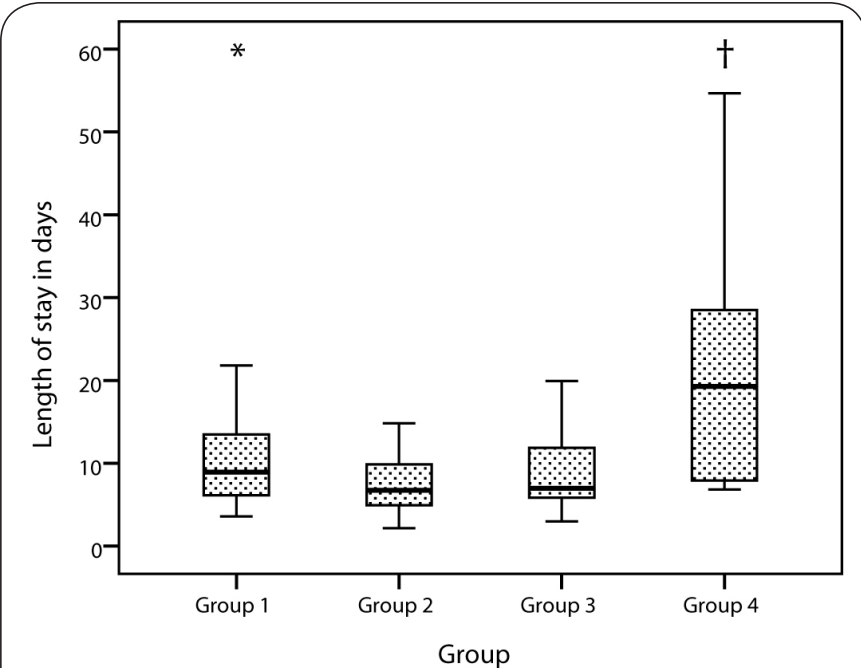

Figure 3. Length of stay (LOS): Boxplot comparing LOS of groups 1 to $4(\leq 24,>24$ to $\leq 48,>48$ to $\leq 72$ and $>72$ hours of epidural analgesia, respectively), results are median and IQR. *: group 1 vs. group $2, p=0.033$. $\dagger$ : group 4 vs. groups 1,2 and 3 , $p=0.036, p<0.001$ and $p<0.001$ respectively.

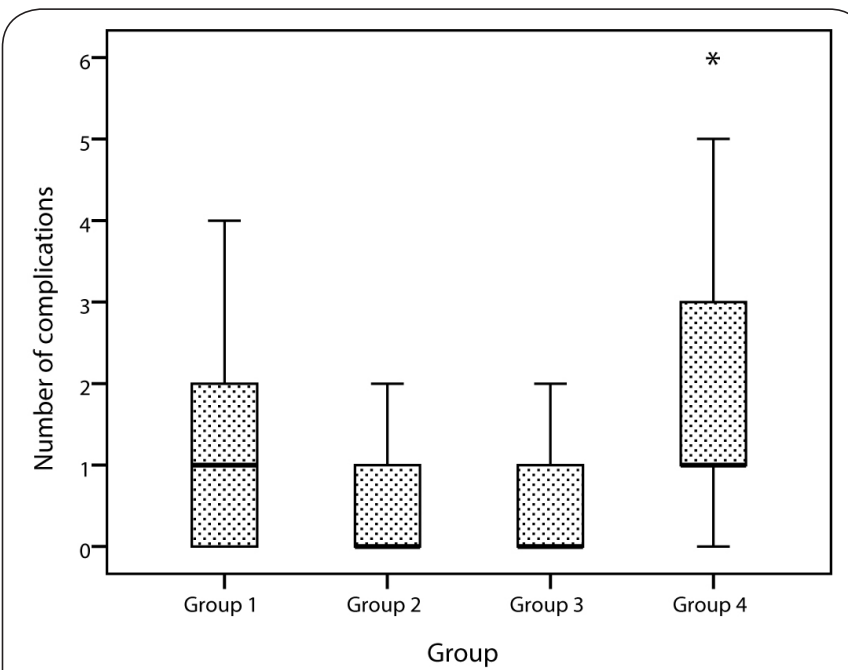

Figure 4. Complication rate: boxplot comparing complication rate of groups 1 to 4 (4 ( $\leq 24,>24$ to $\leq 48,>48$ to $\leq 72$ and $>72$ hours of epidural analgesia, respectively). Results are median and IQR. *: group 4 vs. groups 1, 2 and 3; $p=0.040, p=0.005$ and $p<0.001$ respectively. Note that these include the full 30 day period. See text and Table 2 for further discussion and details.

Table 2. Summary of all registered complications. Data are numbers and percentages. Note that "infection" incorporates a specific, wide, definition. No infection secondary to the epidural occured during the study. See text and Figure 3 for further discussion.

\begin{tabular}{lcccccc}
\hline & \multicolumn{2}{c}{ Early complications ( $\leq 7$ days) } & Late complications (8-30 days) & \multicolumn{2}{c}{ Overall } \\
\hline Complication & Frequency & $\%$ & Frequency & $\%$ & Frequency & $\%$ \\
\hline Infection & 38 & $15.9 \%$ & 70 & $29.3 \%$ & 108 & $45.2 \%$ \\
Wound dehiscence & 6 & $2.5 \%$ & 21 & $8.8 \%$ & 27 & $11.3 \%$ \\
Hematoma/bleeding & 12 & $5.0 \%$ & 1 & $0.4 \%$ & 13 & $5.4 \%$ \\
Cardiac complications & 2 & $0.8 \%$ & 8 & $3.3 \%$ & 10 & $4.2 \%$ \\
Management issue & 3 & $1.3 \%$ & 7 & $2.9 \%$ & 10 & $4.2 \%$ \\
Urinary retention & 6 & $2.5 \%$ & 4 & $1.7 \%$ & 10 & $4.2 \%$ \\
Bowel necrosis/ischaemia & 7 & $2.9 \%$ & 2 & $0.8 \%$ & 9 & $3.8 \%$ \\
Anastomotic dehiscence & 4 & $1.7 \%$ & 5 & $2.1 \%$ & 9 & $3.8 \%$ \\
Ileus & 3 & $1.3 \%$ & 5 & $2.1 \%$ & 8 & $3.3 \%$ \\
Iatrogenic & 4 & $1.7 \%$ & 4 & $1.7 \%$ & 8 & $3.3 \%$ \\
Embolus/thrombus & 1 & $0.4 \%$ & 2 & $0.8 \%$ & 3 & $1.3 \%$ \\
Shock / Sepsis & 2 & $0.8 \%$ & 1 & $0.4 \%$ & 3 & $1.3 \%$ \\
Fever/sepsis & 1 & $0.4 \%$ & 2 & $0.8 \%$ & 3 & $1.3 \%$ \\
Fistula & 0 & $0.0 \%$ & 2 & $0.8 \%$ & 2 & $0.8 \%$ \\
Delirium & 1 & $0.4 \%$ & 1 & $0.4 \%$ & 2 & $0.8 \%$ \\
Others & 7 & $2.9 \%$ & 7 & $2.9 \%$ & 14 & $5.9 \%$ \\
\hline
\end{tabular}

accounted for almost half of all complications, see Table 2. This high percentage may be attributed to a complication being scored if "additional wound care impacting patient comfort or quality of life" occurred. This including during outpatient check-ups, instead of for more medical (eg., CRP elevation, initiation of antibiotics or presence of pus) consideration. This scoring technique is part of a long term observational quality of life study.

\section{Analgesia after termination of EA}

After withdrawal of EA, $22.6 \%$ of patients were started on PCIA. For groups 1 to 4 this was $74.4 \%$ ( 32 cases), $44.4 \%$ ( 20 cases), $1.5 \%$ ( 2 cases) and $4.2 \%$ ( 1 case) respectively. Reasons for withdrawing EA in groups 1 and 2 are summarized in Table 3.

Comparison of groups 1 and 2 revealed that the duration of PCIA did not differ (54.8 \pm 19.2 hrs vs. $45.1 \pm 21.2 \mathrm{hrs}, p=0.094)$. Notably, opioid consumption was higher for group 1, both, in 
Table 3. Overview of reported reasons for the removal of the epidural catheter in groups 1 and 2 ( $\leq 24 \mathrm{~h}$ and $>24$ to $\leq 48 \mathrm{~h}$, respectively). Data are numbers and percentages.

\begin{tabular}{lcc}
\hline Reason & Incidence & $\%$ \\
\hline Pain/inadequate block & 38 & $43.2 \%$ \\
Hypotension & 14 & $15.9 \%$ \\
Technical failure & 13 & $14.8 \%$ \\
Interfering with mobilization (i.e., requested & 10 & $11.4 \%$ \\
removal/overt motor block) & & \\
Fever & 5 & $5.7 \%$ \\
Respirator & 1 & $1.1 \%$ \\
Not recorded & 7 & $8.0 \%$ \\
\hline
\end{tabular}

absolute quantity ( $87.8 \pm 35.2 \mathrm{mg}$ vs. $62.4 \pm 39.3 \mathrm{mg} p=0.025)$ and when adjusted for duration $\left(1.7 \pm 0.2 \mathrm{mg} \cdot \mathrm{h}^{-1} \mathrm{vs} .1 .2 \pm 0.1\right.$ $\left.\mathrm{mg} \cdot \mathrm{h}^{-1}, p=0.044\right)$.

\section{Post-hoc analysis}

Six patients were outliers in terms of length of stay. Excluding these patients from the LOS analysis, alters overall LOS only slightly to 7.8 (IQR 7) and 8.8 (IQR 7), 6.8 (IQR 4), 7.0 (IQR 6) and 17.8 (IQR 20) for groups 1 to 4, respectively, without altering the statistical results.

\section{Discussion}

The ERAS guidelines strongly advocate the use of epidural analgesia (EA). However, its value beyond postoperative day 2 ( $\leq 48$ hours) has been challenged despite ERAS suggesting use up to 72 hours [1]. Our data show that an epidural analgesia (EA) regimen aiming at more than 48 but less than 72 hours is associated with the shortest length of stay (LOS) and the lowest complication rate. EA for less than 24 hours is associated with an increased LOS. There is no difference in outcome measures between groups 2 and 3 ( $>24$ to $\leq 48$ and $>48$ to $\leq 72$ hours, respectively), which supports the use of the third 24 hour period. Extension of EA use for more than 72 hours (group 4) is associated with increased LOS and complication rate. We are, to our knowledge, the first group to approach epidural analgesia as one aspect within a conglomerate of factors within ERAS using a value-added versus hinder due to confounders (eg., LOS and complication rate) methodology, in order to observe its effect.

A common EA associated adverse effect is hypotension $[3,4]$; a potential challenge in the fluid restricted ERAS setting during abdominal surgery. In $16 \%$ of our cases, hypotension judged clinically relevant (eg., suspected hypoperfusion) was the reason for early termination of the epidural analgesia. Interestingly, in our series, the risk of this occurring was not associated with the initial postoperative transfer choice of a middle or high dependency (cyclic monitoring q. 15 minutes) unit when compared to low-care (periodic or nurse-driven monitoring q. 1-2 hours) unit.
ERAS suggests that hypotension should be treated based on assessment of the patient's fluid status. Such assessment can, clinically, be difficult as it is influenced by preoperative hydration, insensible loss, the EA and the surgery itself. It may require an extra intervention such as the placement of a central venous access, indwelling arterial line and blood gas analysis, each with their own morbidity. In case of a hypotension in a normovolemic patient, ERAS states that vasopressors should be considered first. Fluid therapy, and then restrictive, judicial use, is only advocated in hypovolemic patients [2]. However, on induction of an epidural block, colonic red cell flux and mesenteric arterial flow both decrease, paralleling changes in mean arterial pressure [5] including its response to fluid challenges. Reduced splanchnic blood flow remains unresponsive to fluid therapy [5]. These changes in perfusion may interfere with anastomotic viability and healing. There was no association between anastomotic dehiscence or bowel necrosis with EA [4]. However, while EA has not been associated with anastomotic failure, treatment of EA induced hypotension has been associated with negative outcomes. Zakrison et al., (2007) concluded that the use of vasopressors in patients carried an independent, threefold, increased risk of anastomotic leakage [6]. On the other hand, excessive fluid therapy may dilute the oxygen carrying capacity of the blood particularly at the peri-anastomotic capillary level, and in conjunction with this may lead to bowel edema, potentially compromising anastomotic healing through increase in diffusion lengths [7].

In general, EA regimes using either pure local anesthetics or those combining local anesthetics with epidural opioids, provide superior pain relief when compared to systemic opioid regimen in patients who have undergone abdominal surgery $[4,8,9]$. EA is deemed safe as major complications related to placement or use rarely occur $[10,11]$. EA has been suggested to reduce the physiological stress response during the acute response period after a systemic insult, including factors such as oedema related ileus [11]. In a randomized clinical trial, Senagore et al., (2003) found improved analgesia with EA, but found no reduction in length of stay when compared to $\mathrm{PCIA}$, noting that their study group received EA for only 18 hours [12] which, in line with our data, seems overly brief. They describe improved gastrointestinal function and a reduced incidence of postoperative ileus with EA without opioids. We were unable to study this in our population as our patients all received an epidural infusion with standard solutions of ropivacaine with sufentanil.

In line with this, in our study, if EA was withdrawn within 48 hours, $43 \%$ was due to the patient experiencing pain (eg., inadequate block resistant to boluses) and another $15 \%$ following technical failure. In such cases, our strategy requires consideration of the use of PCIA. The ERAS guidelines advocate avoidance of parental opioids and PCIA in order to limit the risk of opioid side effects [2], relegating the use of PCIA solely for postoperative pain control after laparoscopic 
surgery and even then suggesting it should be minimized [2]. At the same time, use of an opioid within the ERAS EA regimen is acceptable.

The isolated effect of epidural opioids on surgical complications has been eloquently investigated by Finucane et al., (2001) [13].Their study showed that the addition of fentanyl to a ropivacaine infusion decreased infusion rates, improved post-operative analgesia and a decreased chance of premature EA termination caused by inadequate pain relief. However, they noted more adverse events, particularly hypotension and nausea in the fentanyl group [13].

Fat-soluble opioids such as fentanyl and sufentanil, used for EA are known to migrate to the systemic circulation and have effects other than those mediated by spinal and supraspinal sites $[14,15]$. Prospective studies have even described comparable plasma opioid concentrations when epidural is compared to parental infusion [14-16], while others find that equivalent to somewhat higher doses of sufentanil are required during opioid-only epidural compared to intravenous infusion to achieve the same level of analgesia $[17,18]$. The migration of sufentanil might explain why the complication rate in group 2 was not negatively influenced, compared to group 3 , despite receiving significantly and clinically relevantly more parenteral.

It is surprisingly common that EA is withdrawn prior to completing an intended period of use [19]. This may be due to technical issues, breakthrough pain unresponsive to boluses or increased infusion rates or the occurrence of adverse effects [19]. In our data, as well as in a multivariate analysis [3], early (group 1 \& 2, eg., up to 48 hour use) epidural withdrawal was associated with increased LOS, as were continued use of intravenous fluids, failure of early mobilization and recatheterization [20]. Causality in our study remains unclear. However, it does suggest that early withdrawal of EA should trigger a warning flag in the clinical pathway, as it may be an early sign of complications or a protracted course.

In parallel, early patient mobilization is emphasized by ERAS, due to its short term beneficial effects [21] and even more due to negative effects in its absence $[20,22]$. Our results show that, despite the APS attention for good sensory and limited motor blocks, in at least $11 \%$ of our cases EA was documented as having interfered with early mobilization. Duff et al., (2013) reported a prevalence of $21.6 \%$ for EA interfering with mobilization after lower gastrointestinal surgery [23]. Any causal relationship is, however, unclear within the ERAS conglomerate: hospital policy stresses patient safety requiring two nurses for mobilization to a chair, nursing concerns for movement induced hypotension or shifts in blocks, as well as threats to other indwelling catheters and the patient's clinical state are all uncontrollable and subjective factors in the choice to delay or limit mobilization [24].

This issue is not limited to EA, as PCIA may also limit mobilization through sedation. In our series, the use of PCIA did not lead to higher sedation scores compared to EA, as has been described elsewhere [4], however overall opioid consumption in our patients was low $(1.2 \pm 0.1 \mathrm{mg} \cdot \mathrm{h}-1$ to $1.7 \pm 0.2 \mathrm{mg} \cdot \mathrm{h}-1)$. These results suggest that mobilization is a typical conglomerate multi-factorial activity within ERAS: we were unable to find evidence that associated removal of the epidural within 48 to 72 hours with influence on mobilization.

This study has some limitations. Our study focused primarily on EA as one aspect within ERAS clinical pathway. Length of stay may have been influenced by confounders or other possible factors, guideline or patient related. We recognize that, in this exploratory study, it remains unclear if maintenance of EA for more than 72 hours has a causal relationship, leading to an increased LOS, or conversely, whether EA is maintained longer as an effect, in already complicated cases because they have a persisting analgesia need. ERAS itself is multicomponent and clustered, with numerous interrelationships influencing the cascade of events, finally determining outcome, despite its explicit goal of standardization. Whether a Hawthorne effect is also a major factor, remains to be determined as ERAS becomes the routine. We recognize that, with the small numbers of patients in the analysis, statistical significance may not equate to clinical relevance. We also note that because the APS routinely visits twice a day unless otherwise requested, HEA was not continuous and was pooled for analysis.

\section{Conclusion}

Epidural analgesia (EA) is a key aspect in early recovery after surgery (ERAS) procedures. Optimal duration has been suggested to be 48 hours instead of up to 72 hours. We found that maintaining EA beyond 48 hours postoperatively is not associated with prolonged LOS or an increased complication rate. Its use up through the third 24 hour period decreases change-over to PCIA. Use of EA for less than 24 hours or more than 72 hours seems to be associated with increased LOS. In addition, EA use for more than 72 hours seems to be associated with an increased complication rate. As a key factor in the ERAS clinical pathway, early withdrawal of EA should raise a yellow flag as it may be an early sign of complications. Further research, isolating epidural effects with the conglomerate of ERAS activities are warranted.

\section{Competing interests}

The authors declare that they have no competing interests.

\section{Authors' contributions}

\begin{tabular}{|l|c|c|c|c|c|}
\hline Authors' contributions & JK & JPB & RCB & SK & GJN \\
\hline Research concept and design & $\sqrt{ }$ & $\sqrt{ }$ & -- & -- & $\sqrt{ }$ \\
\hline Collection and/or assembly of data & $\sqrt{ }$ & $\sqrt{ }$ & -- & -- & -- \\
\hline Data analysis and interpretation & $\sqrt{ }$ & -- & -- & -- & $\sqrt{ }$ \\
\hline Writing the article & $\sqrt{ }$ & -- & $\sqrt{ }$ & $\sqrt{ }$ & $\sqrt{ }$ \\
\hline Critical revision of the article & $\sqrt{ }$ & -- & $\sqrt{ }$ & $\sqrt{ }$ & $\sqrt{ }$ \\
\hline Final approval of article & $\sqrt{ }$ & $\sqrt{ }$ & $\sqrt{ }$ & $\sqrt{ }$ & $\sqrt{ }$ \\
\hline Statistical analysis & $\sqrt{ }$ & -- & -- & -- & -- \\
\hline
\end{tabular}




\section{Acknowledgement}

We would like to extend our thanks to Prof. A. Noordergraaf, Univ. of Pennsylvania, for his critical reading, suggestions and support as well as to Dr. J. Heisterkamp; W.J.B.M. Jansen RN, MPA, lead ERAS nurse and A. Venema RN, MPA, for their assistance with data collection, access to databases and clarifications.

\section{Publication history}

Editor: Étienne de Médicis, Centre Hospitalier Universitaire de Sherbrooke, Canada.

Senior Editor: Michael Paech, The University of Western Australia, Australia.

Received: 01-Jul-2013 Revised: 5-Aug-2013

Re-Revised: 31-Aug-2013 Accepted: 03-Sep-13

Published: 16-Sep-2013

\section{References}

1. Gillissen F, Hoff C, Maessen JM, Winkens B, Teeuwen JH, von Meyenfeldt $\mathrm{MF}$ and Dejong $\mathrm{CH}$. Structured synchronous implementation of an enhanced recovery program in elective colonic surgery in 33 hospitals in The Netherlands. World J Surg. 2013; 37:1082-93. | Article | PubMed

1. Gillissen F, Hoff C, Maessen JM, Winkens B, Teeuwen JH, von Meyenfeldt $\mathrm{MF}$ and Dejong $\mathrm{CH}$. Structured synchronous implementation of an enhanced recovery program in elective colonic surgery in $\mathbf{3 3}$ hospitals in The Netherlands. World J Surg. 2013; 37:1082-93. | Article I PubMed

2. Gustafsson UO, Scott MJ, Schwenk W, Demartines N, Roulin D, Francis $\mathrm{N}$, McNaught CE, Macfie J, Liberman AS and Soop M et al. Guidelines for perioperative care in elective colonic surgery: Enhanced Recovery After Surgery (ERAS((R))) Society recommendations. World I Surg. 2013; 37:259-84. | Article | PubMed

3. Block BM, Liu SS, Rowlingson AJ, Cowan AR, Cowan JA, Jr. and Wu CL. Efficacy of postoperative epidural analgesia: a meta-analysis. JAMA. 2003; 290:2455-63. | Article | PubMed

4. Marret $E$, Remy $C$ and Bonnet $F$. Meta-analysis of epidural analgesia versus parenteral opioid analgesia after colorectal surgery. Br J Surg. 2007; 94:665-73. | Article | PubMed

5. Gould TH, Grace K, Thorne G and Thomas M. Effect of thoracic epidural anaesthesia on colonic blood flow. Br J Anaesth. 2002; 89:446-51. Article I PubMed

6. Zakrison T, Nascimento BA, Jr., Tremblay LN, Kiss A and Rizoli SB. Perioperative vasopressors are associated with an increased risk of gastrointestinal anastomotic leakage. World J Surg. 2007; 31:1627-34. Article I PubMed

7. Marjanovic G, Villain C, Juettner E, zur Hausen A, Hoeppner J, Hopt UT, Drognitz $\mathrm{O}$ and Obermaier $\mathrm{R}$. Impact of different crystalloid volume regimes on intestinal anastomotic stability. Ann Surg. 2009; 249:181-5. | Article | PubMed

8. Jorgensen $\mathrm{H}$, Wetterslev J, Moiniche $\mathrm{S}$ and Dahl JB. Epidural local anaesthetics versus opioid-based analgesic regimens on postoperative gastrointestinal paralysis, PONV and pain after abdominal surgery. Cochrane Database Syst Rev. 2000; CD001893. | Article I PubMed

9. Werawatganon $T$ and Charuluxanun S. Patient controlled intravenous opioid analgesia versus continuous epidural analgesia for pain after intra-abdominal surgery. Cochrane Database Syst Rev. 2005; CD004088. | Article | PubMed

10. Cook TM, Counsell D and Wildsmith JA. Major complications of central neuraxial block: report on the Third National Audit Project of the Royal College of Anaesthetists. Br J Anaesth. 2009; 102:179-90. | Article | PubMed

11. Freise $\mathrm{H}$ and Van Aken HK. Risks and benefits of thoracic epidural anaesthesia. Br J Anaesth. 2011; 107:859-68. | Article | PubMed

12. Senagore AJ, Delaney CP, Mekhail N, Dugan A and Fazio VW. Randomized clinical trial comparing epidural anaesthesia and patient-controlled analgesia after laparoscopic segmental colectomy. Br J Surg. 2003; 90:1195-9. | Article | PubMed
13. Finucane BT, Ganapathy S, Carli F, Pridham JN, Ong BY, Shukla RC, Kristoffersson AH, Huizar KM, Nevin K and Ahlen KG. Prolonged epidural infusions of ropivacaine $(2 \mathrm{mg} / \mathrm{mL})$ after colonic surgery: the impact of adding fentanyl. Anesth Analg. 2001; 92:1276-85. | Article | PubMed

14. Glass PS, Estok P, Ginsberg B, Goldberg JS and Sladen RN. Use of patientcontrolled analgesia to compare the efficacy of epidural to intravenous fentanyl administration. Anesth Analg. 1992; 74:345-51. | Article | PubMed

15. Loper KA, Ready LB, Downey M, Sandler AN, Nessly M, Rapp S and Badner N. Epidural and intravenous fentanyl infusions are clinically equivalent after knee surgery. Anesth Analg. 1990; 70:72-5. | Article | PubMed

16. Miguel R, Barlow I, Morrell M, Scharf J, Sanusi D and Fu E. A prospective, randomized, double-blind comparison of epidural and intravenous sufentanil infusions. Anesthesiology. 1994; 81:346-52; discussion 25A-26A. | Article | PubMed

17. Geller E, Chrubasik J, Graf R, Chrubasik S and Schulte-Monting J. A randomized double-blind comparison of epidural sufentanil versus intravenous sufentanil or epidural fentanyl analgesia after major abdominal surgery. Anesth Analg. 1993; 76:1243-50. | Article | PubMed

18. Menigaux C, Guignard B, Fletcher D, Sessler DI, Levron JC and Chauvin $M$. More epidural than intravenous sufentanil is required to provide comparable postoperative pain relief. Anesth Analg. 2001; 93:472-6. | Article | PubMed

19. Hermanides J, Hollmann MW, Stevens MF and Lirk P. Failed epidural: causes and management. Br J Anaesth. 2012; 109:144-54. | Article | PubMed

20. Smart NJ, White P, Allison AS, Ockrim JB, Kennedy RH and Francis NK. Deviation and failure of enhanced recovery after surgery following laparoscopic colorectal surgery: early prediction model. Colorectal Dis. 2012; 14:e727-34. | Article | PubMed

21. Henriksen MG, Jensen MB, Hansen HV, Jespersen TW and Hessov I. Enforced mobilization, early oral feeding, and balanced analgesia improve convalescence after colorectal surgery. Nutrition. 2002; 18:147-52. | Article | PubMed

22. Convertino VA. Cardiovascular consequences of bed rest: effect on maximal oxygen uptake. Med Sci Sports Exerc. 1997; 29:191-6. | Article I PubMed

23. Duff P, Daly $C$ and McCrory C. Ambulatory postoperative ward-based epidural analgesia: a retrospective review of 1,147 cases. Ir J Med Sci. 2013; 182:139-41. | Article | PubMed

24. Lassen K, Soop M, Nygren J, Cox PB, Hendry PO, Spies C, von Meyenfeldt MF, Fearon KC, Revhaug A, Norderval S, Ljungqvist O, Lobo DN and Dejong $\mathrm{CH}$. Consensus review of optimal perioperative care in colorectal surgery: Enhanced Recovery After Surgery (ERAS) Group recommendations. Arch Surg. 2009; 144:961-9. | Article | PubMed

\section{Citation:}

Koolwijk J, Backx JPJM, Bremer RC, Kleinveld S and Noordergraaf GJ. Epidural analgesia as part of a fast track recovery (ERAS) program for elective colonic surgery: just long enough. J Anesthesiol Clin Sci. 2013; 2:27.

http://dx.doi.org/10.7243/2049-9752-2-27 